\title{
Liquid processing of silicon steels using the converter-ladle furnace-circulation degasser route
}

\author{
by E. Keskinkilic*
}

\section{Synopsis}

Electrical steels are used in motors, power generators, and transformers for electrical applications owing to their superior magnetic properties. These properties are attributed to the presence of a significant amount of silicon in the steel composition. Silicon steels are mainly grouped into two categories: grain-oriented (GO) and non-grain-oriented (NGO). The Si content of silicon steels is generally between about $0.50 \%$ and $6.5 \%$. Therefore, silicon steels are further classified as low-, medium-, and highSi steels. In this paper, liquid steel processing practices for certain silicon steel grades are outlined by considering a steelmaking company that integrates a basic oxygen furnace (BOF), a ladle furnace (LF), and an RHtype degassing unit (RH). Possible problems are identified, suggestions are discussed, and conclusions are drawn on the basis of real plant data.

Keywords

silicon steels, liquid steel processing, integrated iron and steelmaking.

\section{Introduction}

Silicon steels are widely used in motors, power generators, and transformers for electrical applications owing to their superior magnetic properties. They are mainly grouped into grain-oriented (GO) and non-grain-oriented (NGO) silicon steel grades. However, the differences in the properties and thermomechanical production of $\mathrm{GO}$ and $\mathrm{NGO}$ grades are outside the scope of this paper. In this study, liquid steel processing of certain silicon steels will be discussed. In the integrated iron and steelmaking process, converters are the primary steelmaking units that are used mainly for decarburization and removal of phosphorus, and for obtaining liquid steel with a specific chemical composition and suitable temperature for secondary steelmaking operations. Ladle furnaces are a type of ladle metallurgy station consisting of electrical and/or chemical heating facilities for adjusting the liquid steel temperature during alloying. Various types of vacuum units are used for decarburization and removal of nitrogen, hydrogen, and sulphur, depending on the metallurgical conditions of the vacuum units. In this study, an actual steel-production company is considered in which the primary steelmaking operation uses a basic oxygen furnace (BOF) converter with
$\mathrm{N}_{2} / \mathrm{Ar}$ bottom blowing, and the secondary steelmaking operations involve (1) a ladle furnace (LF) heated by three graphite electrodes and equipped with $\mathrm{Ar}$ and $\mathrm{N}_{2}$ top/bottom mixing facilities, and (2) an RHtype (circulation) vacuum degassing unit equipped with a top-blowing attachment for oxygen blowing and an Ar-purging system from an up-leg snorkel.

In the following sections, the liquid processing of certain silicon steel grades using this BOF-LF-RH route will be outlined. Possible problems and suggestions will be discussed and conclusions drawn from the real plant data. The findings of this study in relation to liquid steel processing of the selected silicon steel grades are expected to be helpful for engineers working in the steelmaking field as well as the quality and $R \& D$ departments of steelmaking companies.

\section{BOF-LF-RH route}

In the steelmaking shop of a steel-production company, basic oxygen furnaces (BOFs) are used. The converter has a capacity of producing $120 \mathrm{t}$ steel and is equipped with a $\mathrm{N}_{2} /$ Ar bottom bubbling system containing six elements. During the $\mathrm{O}_{2}$ blowing process, which takes on average 18 minutes, temperature measurements and samples for chemical analysis are taken in nearly all primary steelmaking operations. The converters are equipped with modern slag-free tapping systems to minimize the amount of slag carryover.

A number of LFs are available for ladle metallurgy. A typical LF has the same capacity as the converter and is heated with three electrodes, each $45 \mathrm{~cm}$ in diameter. Ar and $\mathrm{N}_{2}$ can be introduced to the system both from the

* Department of Metallurgical and Materials Engineering of Atilim University, Turkey.

(C) The Southern African Institute of Mining and Metallurgy, 2019. ISSN 2225-6253. Paper received Dec. 2017; revised paper received May 2018. 


\section{Liquid processing of silicon steels using the converter-ladle furnace-circulation degasser route}

top lance and from the porous plug at the bottom of the ladle. The other important components are the alloy bins and the $\mathrm{Al}$ and CaSi wire feeding machines. The ladle coming from the converter is first subjected to Ar gas flow from the porous plug for 3 minutes, following which the temperature is measured and a sample is taken for analysis. Depending on the chemical composition requirements of the steel grade to be produced, the necessary alloying materials are introduced into the steel bath. Simultaneously, considering the temperature requirement of the continuous casting machine, the ladle is heated or cooled. Then, the temperature of the steel bath is measured again and a further sample is taken for analysis. Based on the results, the heating or cooling and alloying steps may be repeated. After the Ar gas blowing step followed by sampling, the ladle is ready to be sent to a caster.

An RH-type (circulation) vacuum degasser is used primarily for the production of ultra-low carbon steels. The inner diameter and height of the vessel are $1.7 \mathrm{~m}$ and $7.8 \mathrm{~m}$, respectively. A snorkel with an inner diameter of $0.5 \mathrm{~m}$ is welded to the vessel. The suction capacities ( $k g$ dry air per hour) are 2400 at 67 mbar, 1000 at $6.7 \mathrm{mbar}$, and 600 at 0.67 mbar. Steel to be treated at the vacuum station is tapped from the converter in a rimmed condition and reheated in the LF for around 10 minutes before vacuum treatment. The average process duration in the vacuum degassing unit is 20-25 minutes, depending on the target carbon content. The typical vacuum achieved in the circulation degasser is around 10 mbar. Argon is injected into the up-leg of the snorkel to achieve a circulation rate of approximately $60 \mathrm{t}$ of steel per minute.The vacuum degassing process is performed for approximately 15 minutes. The vacuum degassing vessel is also equipped with a top-blown lance for oxygen saturation and reheating.

\section{Liquid steel processing of silicon steel grades}

There are many grades of silicon steels, based on the silicon content. In general, silicon steels have a Si content ranging from $0.50 \%$ up to $6 \%$ or more. Therefore, they are classified as low-, medium-, and high-Si steels (e.g., AK Steel Corporation, 2007). The chemical compositions of some typical silicon steels produced in the steelmaking industry are given in Table I. The steels listed in Table I are low-Si steel grades in the non-grain-oriented group. As mentioned previously, discussion of the material properties of the different grades of silicon steels is outside the scope of this paper. However, since the magnetic properties of the steel are mostly controlled by the chemical composition, it is beneficial to consider briefly the effects of alloy additions on the magnetic properties. As can be seen from Table I, four elements, namely Si, Al, P, and Mn, are added into the steel bath during liquid steel processing of the silicon steels. Si, the most important addition, decreases the core loss and magnetic permeability. Although not as prominent as $\mathrm{Si}, \mathrm{Al}$ behaves in a similar manner. Importantly, $\mathrm{Al}$ affects the core loss by grain coarsening as well as by inducing changes in the texture or quantity and distribution of impurities. $\mathrm{P}$ and $\mathrm{Mn}$ reduce the core loss by decreasing the eddy current component of the loss. Detailed information about the magnetic properties of NGO steels can be found in Ghosh et al. (2014).

Liquid steel processing routes for Grade-X, Grade-Y, and Grade- $Z$ are shown in Figure 1. One of the most important factors in the selection of the processing route is the carbon content. As can be seen from Table I, the maximum allowable carbon composition of Grade- $\mathrm{X}$ is $0.040 \%$, which is considerably greater than for Grade-Y and Grade-Z. Considering BOF metallurgy, it is impossible to decrease the carbon content to extremely low levels without excessive oxidation of the steel bath. At carbon levels below $0.4 \%$, the rate of decarburization decreases with decreasing carbon content and the consumption of oxygen by oxidation of phosphorus, manganese, and iron and dissolution in the steel bath increases. Even with bottom gas injection (i.e., combined blowing), which provides carbon oxygen product (i.e. [\% C] * [ppm 0]) less than 20 , a heat cannot be blown to a carbon content of $0.025-0.03 \%$ without over-oxidation (Turkdogan, 1996). Therefore, a steel grade with a maximum allowable carbon content of $0.030 \%$ requires further decarburization after the BOF process. For this purpose, a circulation degasser $(\mathrm{RH})$ is used in the ladle metallurgy stage for Grade-Y and Grade-Z steels. As can be seen from Figure 1, the LF step is required for the treatment of Grade-Y and Grade- $Z$ steels as well.

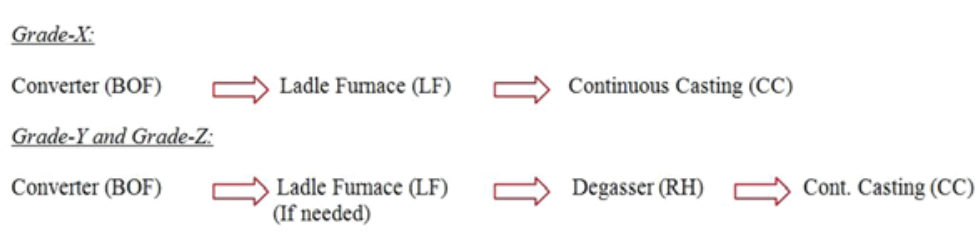

Figure 1-Liquid steel processing routes for the silicon steels listed in Table I

Table I

Specifications of silicon steels produced in the steelmaking company

\begin{tabular}{|l|c|c|c|c|c|c|}
\hline Grade, & C (max.) (\%) & Si (\%) & Mn (\%) & P (\%) & S (max.) (\%) & Al (\%) \\
\hline Grade-X & 0.040 & $1.00-1.40$ & $0.15-0.35$ & $0.06-0.10$ & 0.015 \\
Grade-Y & 0.030 & $1.10-1.50$ & $0.15-0.35$ & $0.06-0.10$ & $0.15-0.45$ \\
Grade-Z & 0.030 & $1.30-1.70$ & $0.15-0.40$ & $0.07-0.10$ & 0.015 & $0.15-0.45$ \\
\end{tabular}




\section{Liquid processing of silicon steels using the converter-ladle furnace-circulation degasser route}

Although this step is not essential for all heats treated in the vacuum degasser, it is included because heating of the ladle during the vacuum treatment, which continues for 20-25 minutes, is not possible. Therefore, the ladle most often requires preheating in the LF to compensate for the heat loss during vacuum degassing.

In the treatment of Grade-Y and Grade-Z steels, deep decarburization is not required because these steels are not regarded as ultra-low carbon ( $<50 \mathrm{ppm})$. Therefore, the vacuum treatment should be performed in such a way that the $\mathrm{C}$ content is below $0.030 \%$, considering the possibility of carbon pickup during alloying in the vacuum station, ladle transportation, and the holding period in the turret and casting process (i.e., C pickup encountered primarily in the tundish and continuous casting mould). This type of vacuum degassing process is called a 'light treatment' and is applied for steels of various grades (Yano et al., 1994).

As mentioned before, the maximum allowable carbon content of Grade-X is $0.040 \%$, which is significantly higher than Grade-Y and Grade-Z. After oxygen blowing in the BOF, the carbon content of Grade-X (average value approx. $0.025 \%$ ) does not require the vacuum treatment (Figure 2 ). Therefore, secondary steelmaking of Grade-X should be confined to the LF. The LF treatment starts with temperature measurement and sampling for chemical analysis after stirring for 3-4 minutes. The liquid steel is transferred from the BOF in the rimmed condition. The first and the most important alloying addition for silicon steels is ferrosilicon, which is an iron-silicon alloy generally containing approximately $75 \% \mathrm{Si}$. The target chemical composition of Grade-X steel requires $1.00-1.40 \% \mathrm{Si}$ content in the bath. Therefore, the target Si value can be set to $1.20 \%$. Although unpublished, a number of trials have shown that approximately $19 \mathrm{~kg}$ of ferrosilicon per ton of steel should be added to the ladle of $120 \mathrm{t}$ steel capacity to facilitate deoxidation and to obtain the desired Si composition. The yield of ferrosilicon in those trials was approximately $80 \%$. Here, it should be indicated that some of the ferrosilicon can be added during tapping of steel from the converter, i.e., before the LF treatment. This alternative practice can be applied when there is a tight production planning schedule. Addition of approximately $2200 \mathrm{~kg}$ of ferrosilicon in the LF

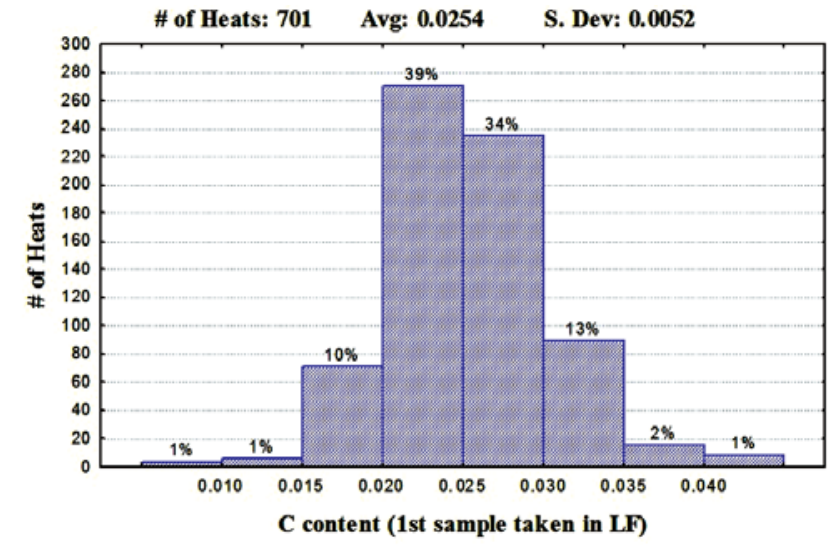

Figure 2-Distribution of $C$ content of Grade- $X$ heats at the beginning of the LF treatment takes considerable time. In most cases, a large amount of alloying material cannot be added to the furnace in a single step. In the steelmaking company considered in this study, approximately $2200 \mathrm{~kg}$ of ferrosilicon is added to the steel bath in four steps, each addition taking approximately 5 minutes, resulting in 20 minutes' additional treatment time. This delay may sometimes create a problem in the continuity of the slab caster. Ladle furnaces are not generally designed for bulk material addition; therefore to add alloys in a shorter time, either a tapping addition practice or custom-designed alloy bins should be adopted, allowing a large amount of material to be added in a single step. The latter method is possibly uneconomical since the LF is used for the treatment of various grades of steel, most of which do not require bulk material addition. After ferrosilicon addition, steel samples are taken for chemical analysis and the temperature is measured.

To facilitate deoxidation and to achieve the required aluminum content of Grade-X, $3 \mathrm{~kg}$ of aluminum is added to the ladle per ton of steel. The aluminum alloy used for this purpose generally contains more than $95 \% \mathrm{Al}$, with the balance being impurities such as $\mathrm{Cu}, \mathrm{Zn}, \mathrm{Mg}$, and $\mathrm{Si}$. Different forms of aluminum such as briquettes, bars, or granules may be used. In the steelmaking company under consideration, the briquette form is mostly preferred for the treatment of silicon steels to ensure a high yield of aluminum, which is approximately $67 \%$ according to trials (Keskinkilic, 2007, unpublished data). Aluminum addition is followed by burnt lime addition to increase the heating rate of the LF. Around $2.5 \mathrm{~kg}$ of burnt lime per ton of steel is used for this purpose.

If the steel from the converter contains less than $0.15 \%$ manganese, the appropriate amount of ferromanganese is added to the steel bath. High-carbon ferromanganese should not be used since it increases the $\mathrm{C}$ content of the steel. Therefore, low-carbon grades, which generally contain less than $1.50 \% \mathrm{C}$, should be chosen. The most important factor causing carbon pickup in the LF treatment is the extended process time. Extension of the treatment duration implies that the time for heating the ladle increases, causing a longer interaction of the electrodes with the steel bath in the ladle. As time passes, the amount of carbon diffusing from the electrodes to the slag, and finally to the steel, increases significantly. Therefore, efforts must be made to complete the LF treatment in an optimum time to prevent $\mathrm{C}$ pick-up. Extended process time also results in N pick-up, which is another important problem facing steelmaking shops.

In the LF process for Grade-X steel, the final addition is to adjust the phosphorus content of the steel. Approximately $2.75 \mathrm{~kg}$ of ferrophosphorus per ton of steel is added to the ladle to obtain a target $\mathrm{P}$ composition of $0.08 \%$. Ferrophosphorus is an iron-phosphorus alloy containing 23-26\% $\mathrm{P}$, with the impurities being mostly $\mathrm{Si}, \mathrm{Cr}, \mathrm{V}, \mathrm{C}$, and $\mathrm{S}$. The yield of ferrophosphorus is approximately $98 \%$. Around 3 minutes of bottom stirring with Ar is followed by sampling for chemical analysis and temperature measurement. To increase the melting rate of ferrosilicon in the liquid steel, stirring with Ar through the top lance is a common practice. If the chemical composition and the temperature are suitable, the ladle is sent to continuous casting. Otherwise, further alloy additions and/or heating or cooling steps are conducted. 


\section{Liquid processing of silicon steels using the converter-ladle furnace-circulation degasser route}

According to the real plant data, the average LF treatment time is approximately 50 minutes, including approximately 17 minutes of heating.

As shown in Table I, the nitrogen content of these grades is specified as $60 \mathrm{ppm}$ (maximum). According to the chemical analysis of samples taken from the continuous casting mould, the typical nitrogen concentrations in these steels are around $40 \mathrm{ppm}$. Therefore, there is no need for special care to achieve the desired nitrogen level.

During continuous casting (CC) of steels in the steelmaking company, three samples for chemical analysis are taken from the CC mould at specific cast lengths of slab strand, depending on the slab width. In practice, the second sample is accepted as the average steel composition of the heat, which is used for determining whether the treated steel is approved or subjected to downgrading. As indicated before, $\mathrm{C}$ pickup during liquid steel processing is one of the problems in steelmaking companies and efforts must be made to maintain the pickup within a predetermined level. The increase in the $\mathrm{C}$ content from the beginning of the $\mathrm{LF}$ treatment (LF1) till the time of second sampling in CC (CC2) more or less shows the extent of $\mathrm{C}$ pickup in ladle metallurgy.

Figure 3 illustrates the values of $\Delta C=C(C C 2)-C(L F 1)$ for the Grade-X heats shown in Figure 2.

The average $C$ pickup is $0.0059 \%$ (59 ppm). Considering the first chemical analysis results at LF (Figure 2), the average $\mathrm{C}$ content of a Grade- $\mathrm{X}$ heat at the middle of $\mathrm{CC}$ (i.e., CC2) can be calculated as CC2 $\mathrm{C}=0.0254+0.0059=$ $0.0313 \%$. This value is acceptable considering the $\mathrm{C}$ content specification for Grade-X, but it is not appropriate for Grade$\mathrm{Y}$ and Grade- $\mathrm{Z}$, for which the maximum allowable $\mathrm{C}$ content is $0.030 \%$. Therefore, for the steelmaking company under consideration, the BOF $\rightarrow$ LF route will not be successful for producing Grade-Y and Grade-Z steels, but an additional decarburization treatment is required, as indicated previously.

As mentioned previously, liquid steel processing of Grade- $\mathrm{Y}$ and Grade- $\mathrm{Z}$ is conducted using the $\mathrm{BOF} \rightarrow \mathrm{LF} \rightarrow \mathrm{RH}$ route. The main difference between the treatment of Grade-Y and Grade- $Z$ and that of Grade- $X$ is that the circulation degassing $(\mathrm{RH})$ step is not needed for Grade-X. Similar to Grade-X, Grade-Y and Grade- $Z$ heats are tapped from the

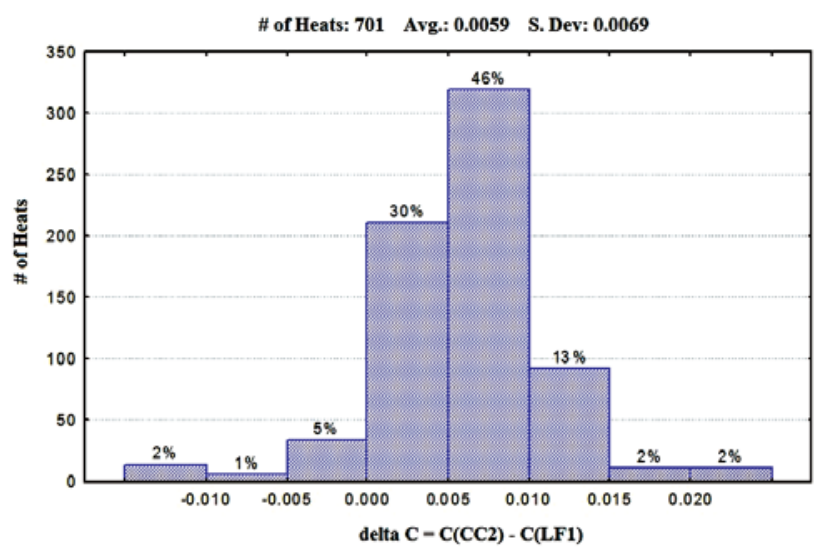

Figure 3-C pickup for the Grade-X heats from the beginning of LF treatment till the time of second sampling in $\mathrm{CC}$, formulated as $\Delta \mathrm{C}=$ C(CC2) - C(LF1) converter in the rimmed condition. The LF step, if needed, is used for heating purposes only. All material additions are therefore conducted in the vacuum degasser. As can be seen from Table I, other than $\mathrm{C}$ and $\mathrm{Si}$, the specifications for Grade-X and Grade-Y are the same. Therefore, the same amounts of aluminum, ferromanganese (if needed), and ferrophosphorus are charged into the ladle in the treatment of Grade-Y. As for the alloy additions, only the amount of ferrosilicon is different: $20 \mathrm{~kg}$ ferrosilicon per ton of steel is added to the ladle to achieve the target composition, which is $1.30 \%$ Si for Grade-Y.

In the secondary steelmaking of Grade-Z, material additions to the ladle are slightly different since the steel is designed with higher concentrations of $\mathrm{Si}, \mathrm{Al}, \mathrm{Mn}$, and $\mathrm{P}$. Correspondingly, the alloy additions in the treatment of Grade- $\mathrm{Z}$ are the highest among the three grades. The target Si content is $1.50 \%$; therefore, $23.3 \mathrm{~kg}$ of ferrosilicon per ton of steel is added to the steel bath. Other material additions are $3.33 \mathrm{~kg}$ of aluminum, $1.67 \mathrm{~kg}$ of ferromanganese (if needed), and $3 \mathrm{~kg}$ of ferrophosphorus per ton of steel.

As indicated previously, light treatment' is applied during circulation degassing of Grade-Y and Grade-Z. There is no need to decrease $C$ to ultra-low levels since the allowable $\mathrm{C}$ compositions of both grades do not need deep decarburization. Therefore, it is straightforward to satisfy the $\mathrm{C}$ requirement in both grades. A carbon content of approximately $0.010 \%$, which is well below the specification value, is achieved at the end of degassing. Most often, the amount of $\mathrm{C}$ pickup after $\mathrm{RH}$ treatment is therefore not a major concern. The second sampling in $\mathrm{CC}$ shows that $\mathrm{CC} 2$ values for both grades are below $0.015 \%$. Distributions of $\mathrm{C}$ contents for Grade-Y and Grade-Z are presented in Figure 4 and Figure 5, respectively.

In the RH treatment of Grade-Y and Grade-Z, some additional costs are incurred due to the extra materials required for those grades. The first item is related to the $\mathrm{RH}$ snorkel lining life. In the liquid processing of low-carbon steels, $8-10$ heats can be treated without snorkel maintenance. On the other hand, in the case of silicon steels, this life is not longer than five heats because of severe interaction of silicon steel with the alumina-based snorkel

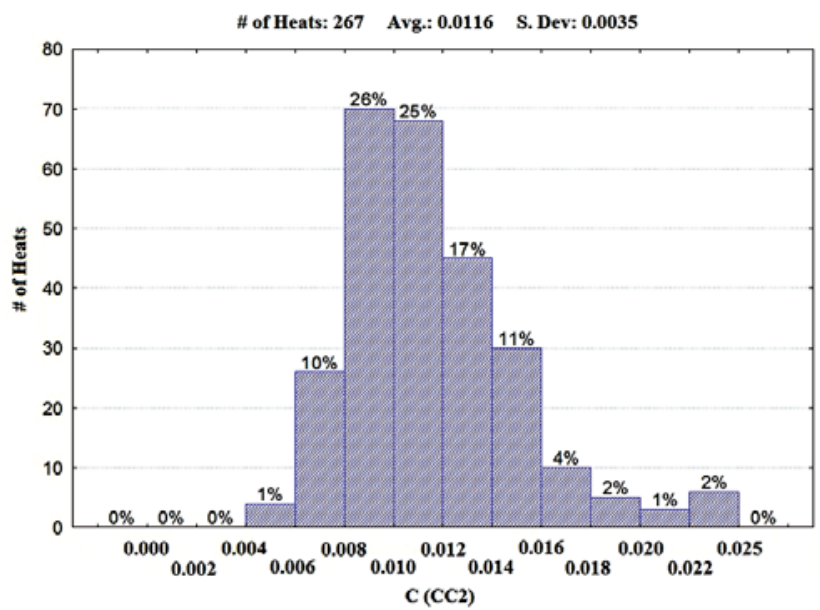

Figure 4-Distribution of $C$ content of Grade-Y heats at CC (CC2 values) 


\section{Liquid processing of silicon steels using the converter-ladle furnace-circulation degasser route}

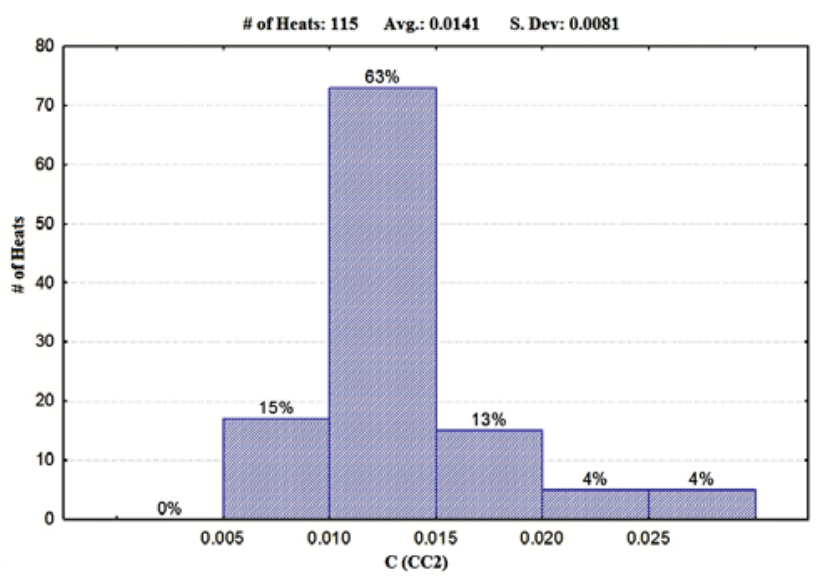

4. Treatment of Grade-Y and Grade- $Z$ in RH is straightforward as far as the $C$ content requirements of these grades are concerned. Including $C$ pick-up, both grades have an average $\mathrm{C}$ content below $0.015 \%$ at $\mathrm{CC}$. This is considerably lower than the maximum allowable $\mathrm{C}$ content, which is $0.030 \%$ for Grade-Y and Grade- $Z$.

5. Three important additional costs are incurred in the $\mathrm{RH}$ treatment of Grade-Y and Grade-Z.

(i) The snorkel lining life for silicon steels is shorter than that for low-carbon and ultra-low-carbon grades because of the severe interaction between the silicon steels and alumina-based lining. This causes consumption of more lining material in the processing of silicon steels.

Figure 5-Distribution of C content of Grade-Z heats at CC (CC2 values)

lining. Therefore, more lining material is used when silicon steels are treated in the vacuum degassing unit. The second item is related to the $\mathrm{RH}$ plant capacity, which is more crucial than the lining material cost. Most RH plants, including the one in the steelmaking company under consideration, have two vacuum chambers, one of which will be in operation while the other is idle. As an example, at the end of the treatment of seven ultra-low carbon heats, the chamber is allowed to cool down for snorkel maintenance. The time needed for the maintenance of both snorkels is around 6 hours. Therefore, 14 heats can be treated in 30 hours. Because of the severity of refractory erosion in the processing of silicon steels, this loop can be a maximum of 8 heats in 20 hours. Therefore, the RH plant capacity decreases by about $15 \%$ due to the snorkel maintenance required when silicon steels are processed, compared to ultra-low carbon grades. In addition to the first and second items, a third item should also be considered: bulk alloying additions in the treatment of silicon steels in RH cause an increase in the total $\mathrm{RH}$ process time. Together with the addition of the amount of alloying materials per ton of steel indicated previously, the total $\mathrm{RH}$ process time increases from 20-25 minutes to 30-35 minutes, causing a decrease in the RH plant capacity.

\section{Conclusions}

Liquid steel processing of low-Si non-grain-oriented steels was examined using the real plant data from a steelmaking company. The following conclusions are drawn.

1. C content is one of the most important factors for the selection of the processing route. Grade- $\mathrm{X}$ can be produced with the BOF $\rightarrow$ LF route, whereas Grade- $\mathrm{Y}$ and Grade- $\mathrm{Z}$ must be treated in $\mathrm{RH}$.

2. Large amounts of alloying additions cause delays in the treatment of all the grades under consideration, regardless of the processing route.

3. C pickup is one of the chief risks in the processing of Grade-X. The average increase in $\mathrm{C}$ content from the beginning of LF treatment till CC is reported as $0.0059 \%$. Extended LF process times should be avoided as much as possible. (ii) The RH plant capacity decreases because of the increased maintenance required. The $\mathrm{RH}$ plant capacity decreases by about $15 \%$ due to snorkel maintenance when silicon steels are processed, compared to when ultra-low carbon grades are processed.

(iii) The RH plant capacity decreases with an increased time for alloying, extending the total RH process time. Such additional costs must be taken into consideration when determining the cost of Grade$\mathrm{Y}$ and Grade- $\mathrm{Z}$ processing.

of course, such additional costs are not confined to the liquid steel processing part alone. Hot rolling of silicon steels also includes certain costs that are significantly higher than the value for the liquid steel processing stage. However, this it is outside the scope of this paper.

6. For the steelmaking company considered in this study, the possible treatment of grain-oriented grades (e.g., containing 3-3.5\% Si) by either the BOF $\rightarrow$ LF or the $\mathrm{BOF} \rightarrow \mathrm{LF} \rightarrow \mathrm{RH}$ route necessitates the following:

> If possible, new alloy bins should be added to LF and RH. Incorporating certain changes, alloy addition (5500-6500 kg of ferrosilicon must be added per heat) should be conducted within a short time, or the practice of addition during tapping should be applied.

- A large ferrosilicon addition causes a decrease in the amount of hot metal charged to the BOF per unit time. The decrease in the hot-metal treatment capacity of the BOF should be considered for the production of grainoriented silicon steel grades.

\section{References}

AK SteEl CORPoration. 2007. http://www.aksteel.com/pdf/markets_products/ electrical/mag_cores_data_bulletin.pdf [accessed 19 July 2017].

Ghosh, P., Снromiк, R.R., KNight, A.M., and WaKade, S.G. 2014. Effect of metallurgical factors on the bulk magnetic properties of non-oriented electrical steels. Journal of Magnetism and Magnetic Materials, vol. 356. pp. $42-51$

TuRKDogan, E.T. 1996. Fundamentals of Steelmaking. Institute of Materials, UK.

Yano, M., Harashima, K., Azuma, K., Kitamura, S., Inomoto, T., and Nagahama, H. 1994. Recent advances in ultralow-carbon steel refining technology by vacuum degassing processes. Nippon Steel Technical Report no. 61. UDC669.18-982. Tokyo, Japan. 